\title{
The four pillars of rheumatic heart disease control
}

The National Department of Health has promulgated the first week of August as National Rheumatic Fever Week ever since rheumatic fever was made a notifiable condition in 1989 The results of the Heart of Soweto Study, however, show that very little progress has been made in reducing the burden of rheumatic heart disease over the past 20 years. This prospective study of 4005 patients with heart disease who presented at Chris Hani Baragwanath Hospital during 2006/07 showed that $960(24 \%)$ had valvular heart disease. ${ }^{1}$ The incidence of new cases of rheumatic heart disease for those aged $>14$ years in Soweto was 23.5 cases $/ 100000$ per annum, which puts this urban community among the high-incidence communities of the world. It is not surprising that this preventable condition remains common, because of inadequate implementation of the guideline for the prevention of rheumatic fever in South Africa. ${ }^{2}$ A recent study showed that very few paediatricians were aware that rheumatic fever is a notifiable condition, and that the national notification system administered by the Department of Health was dysfunctional. ${ }^{3}$

\section{What is to be done?}

Rheumatic Fever Week 2010 offers health professionals, administrators and planners an opportunity to re-discover the four pillars of control of rheumatic fever and rheumatic heart disease, which are enunciated in the national guideline for the prevention of rheumatic fever in primary care. ${ }^{4}$ The first pillar is education of the public, health care professionals, health administrators and health policy makers about the causes, treatment and prevention of rheumatic fever. Public and professional education in particular leads to better case ascertainment and is the essential first step for a successful prevention programme. ${ }^{5}$ The second pillar is primary prevention through treatment of suspected streptococcal sore throat with penicillin, based on a syndromic approach to the assessment of pharyngitis. ${ }^{6}$ This approach was applied to great effect in Costa Rica and Cuba. ${ }^{7,8}$

The third pillar of rheumatic fever and rheumatic heart disease control is secondary prevention through registerbased penicillin prophylaxis. ${ }^{9}$ It is critical that all health centres have registers of their patients with rheumatic fever and rheumatic heart disease to ensure compliance with secondary prophylaxis with penicillin. It is also important to know that lifelong penicillin prophylaxis is recommended for patients with a history of heart failure or previous surgery for rheumatic heart disease.$^{10}$ Finally, the fourth pillar of an effective prevention strategy is surveillance through notification of acute rheumatic fever, which is mandatory in terms of South Africa law. ${ }^{3}$ Unfortunately over $50 \%$ of patients with rheumatic heart disease do not have a history of acute rheumatic fever. Making the first episode of rheumatic heart disease a notifiable condition should therefore be considered. ${ }^{1}$ The addition of the first episode of rheumatic heart disease as a notifiable condition would provide a complete national picture of the incidence of rheumatic fever and rheumatic heart disease in South Africa.

South Africa needs to learn from the examples of Cuba, Costa Rica, and the French Caribbean islands of Martinique and Guadeloupe, who have implemented a comprehensive strategy based on the four pillars of rheumatic heart disease control, which has resulted in the virtual elimination of the disease in their countries within $10-15$ years. ${ }^{5,7}$, Africa has lagged behind the other regions of the world in rheumatic fever control, partially because of neglect of the widespread treatment of suspected streptococcal sore throat with penicillin. ${ }^{6}$ The Pan African Society of Cardiology has called on the Ministries of Health in Africa to implement a programme of Awareness Raising, Surveillance, Advocacy and Prevention (the A.S.A.P. Programme) to deal with the scourge of the disease on the continent. ${ }^{11,12}$ The time has come for health care professionals, policy makers and the public to join the campaign to make rheumatic fever history in our lifetime.

\section{Bongani M Mayosi \\ Department of Medicine \\ Groote Schuur Hospital and \\ University of Cape Town}

Corresponding author: B Mayosi (bongani.mayosi@uct.ac.za)

\section{References}

1. Sliwa K, Carrington M, Mayosi BM, Zigiriadis E, Mvungi R, Stewart S. Incidence and characteristics of newly diagnosed rheumatic heart disease in urban African adults: insights from the Heart of Soweto Study. Eur Heart J 2010; 31: 719-727.

2. Robertson KA, Volmink JA, Mayosi BM. Lack of adherence to the national guidelines on the prevention of rheumatic fever. S Afr Med J 2005; 95: 52-56.

3. Nkgudi B, Robertson KA, Volmink J, Mayosi BM. Notification of rheumatic fever in South Africa - evidence for underreporting by health care professionals and administrators. $S$ Afr Med J 2006; 96: 206-208.

4. National Guidelines on the Primary Prevention and Prophylaxis of Rheumatic Fever and Rheumatic Heart Disease for Health Professionals at Primary Level. Pretoria: Department of Health, 1997.

5. Bach JF, Chalons S, Forier E, et al. 10-year educational programme aimed at rheumatic fever in two French Caribbean islands. Lancet 1996; 347: 644-648.

6. Karthikeyan G, Mayosi BM. Is primary prevention of rheumatic fever the missing link in the control of rheumatic heart disease in Africa? Circulation 2009; 120: 709-713.

7. Arguedas A, Mohs E. Prevention of rheumatic fever in Costa Rica. J Pediatr 1992; 121: 569-572.

8. Nordet P, Lopez R, Duenas A, Sarmiento L. Prevention and control of rheumatic fever and rheumatic heart disease: the Cuban experience (1986-1996-2002). Cardiovasc J Afr 2008; 19: $135-140$

9. McDonald M, Brown A, Noonan S, Carapetis JR. Preventing recurrent rheumatic fever: the role of register based programmes. Heart 2005; 91: 1131-1133.

10. World Health Organization. Rheumatic fever and rheumatic heart disease: Report of a WHO expert panel, Geneva 29 October - 1 November 2001. WHO Tech Rep Ser 2004; No. 924

11. Mayosi B, Robertson K, Volmink J, et al. The Drakensberg declaration on the control of rheumatic fever and rheumatic heart disease in Africa. S Afr Med J 2006; 96(3 Pt 2): 246.

12. Robertson KA, Volmink JA, Mayosi BM. Towards a uniform plan for the control of rheumatic fever and rheumatic heart disease in Africa - the Awareness Surveillance Advocacy Prevention (A.S.A.P.) Programme. S Afr Med J 2006; 96(3 Pt 2): 241-245. 